Note: This is a pre-copy-editing, author-produced PDF of an article accepted for publication in Journal of Applied Social Psychology following peer review. The definitive publisher-

authenticated version [Agostinalli G and Morgan M (2003) Social distancing in adolescents' perceptions of alcohol use and social disapproval: The moderating roles of culture and gender', Journal of Applied Social Psychology, 33(11), 2354-2372] is available online at http://www3.interscience. wiley.com/journal/118531277/toc

\title{
Social Distancing in Adolescents' Perceptions of Alcohol Use and Social Disapproval: The Moderating Roles of Culture and Gender'
}

\author{
GINA AGOSTINELLI ${ }^{1,2}$ AND JOEL w. GRUBE \\ Prevention Research Center Berkeley, California
}

MARK MORGAN

St. Patrickk College Drumcondra, Dublin, Ireland

Corresponding author: GINA AGOSTINELLI, E-mail: gina@prev.org

Published in Journal of Applied Social Psychology, 2003, 33(11), 2354-2372

Copyright: Wiley-Blackwell

\begin{abstract}
College students attribute more conservative attitudes and behaviors concerning alcohol use to themselves and progressively less conservative attitudes and behaviors to their friends and more distal peers. We examined whether a similar social-distancing effect would occur with adolescents in America and Ireland. Students $(\boldsymbol{n}=2,554)$ attributed the most conservative drinking frequency to themselves and progressively less conservative frequencies to their best friends, other good friends, other students their age at their own school, and other students their age at other schools, respectively. Similarly, adolescents attnbuted more disapproval of drinking to their best friends and progressively less conservative disapproval to other good friends, other students their age at their own school, and other students their age at other schools, respectively. As predicted, more social distancing occurred among Americans (relative to Irish) and girls (relative to boys).
\end{abstract}

Weinstein (1980) coined the term unrealistic optimism to describe the belief that others are more likely than oneself to be victims of misfortune. Perloff (1983) labeled this same social comparison bias the illusion of unique invulnerability and demonstrated that it extends to a wide range of negative health and safety outcomes (Perloff \& Fetzer, 1986). It is also present in college students' estimates for negative outcomes resulting from drinking (Baer \& Carney, 1993). Specifically, fraternity and sorority members judge the typical member of their fraternity or sorority, and a typical student at their university, as having more drinking-related problems than themselves and their close friends. They also define certain drinkingrelated behaviors as more problematic for others than for themselves. Such biased

\footnotetext{
1 'The first author was supported by NIAAA Grant \#AA11680 in preparing the present manuscript. The second author was supported by NIAAA Grant \#AA12136. Data collection was funded by NIAAA Grant \#AA08097.

2 2Correspondence concerning this article should be addressed to Gina Agostinelli, Prevention Research Center, 1995 University Avenue, Suite 450, Berkeley, CA 94704. E-mail: gina@prev.org
} 
judgments are explained as motivated downward comparisons. That is, people perceive others to be less fortunate and more at risk for negative outcomes in order to maintain more positive views of themselves (Perloff, 1983; vanderpligt, Otten, Richard, \& vandervelde, 1993; Weinstein, 1982; Wills, 1981). Accordingly, the strength of such biases increases as the outcomes being judged are rated more negatively (Gerrard, Gibbons, \& Warner, 199 1).

Comparisons of one's drinking behaviors to others' drinking behaviors also can be self-serving. Just as one may self-protectively distance oneself from negative drinking-related outcomes by judging others' risks for such outcomes as more likely than one's own, one may distance oneself from negative self-implications by judging others' drinking behaviors as more extreme. One's own level of drinking can then appear more moderate and justifiable. Indeed, college students reliably attribute the most conservative drinking to themselves, less conservative drinking to their close friends, and the most liberal drinking to others more generally (Baer, Stacy, \& Larimer, 1991). Beck and Treiman (1996) presented this same social-distancing effect for American adolescents' judgments of a variety of drinking-related behaviors, although statistical tests were never reported to test the significance of the effect. Because adolescents' perceptions of others' drinking predict their own drinking (e.g., Gerrard, Gibbons, Benthin, \& Hessling, 1996; Grube \& Morgan, 1990; Morgan \& Grube, 1991; Petraitis, Flay, \& Miller, 1995; Windle, Shope, \& Bukstein, 1996), the present study will determine whether the social-distancing effect observed in college students (Baer et al., 1991) will reliably extend to adolescents, and the extent to which this effect is moderated by culture and gender.

Because adolescents' perceptions of others' approval for their drinking also reliably predict their drinking (e.g., Grube \& Morgan, 1990; Morgan \& Grube, 1991; Petraitis et al., 1995; Windle et al., 1996), the present study will determine whether a selfserving social-distancing effect also occurs for these perceptions, and the extent to which culture and gender moderate this effect. Specifically, attributing more extreme and permissive approval norms to a generalized other than to one's friends can avoid the negative self-implications of having friends who hold questionable social attitudes. In general, self-serving judgments extend more readily to those with whom we identify (Burger, 1981; Pettigrew, 1979). Indeed, perceiving others as more extreme than one's friends extends beyond risk estimates (Baer \& Carney, 1993; Linville, Fischer, \& Fischhoff, 1993; Perloff \& Fetzer, 1986) and perceived drinking behavior (Baer et al., 1991), to judged attitudes toward sex (Agostinelli \& Seal, 1998) and toward alcohol use (Prentice \& Miller, 1993). For example, college students assign more extreme attitudes concerning alcohol use to the average student than to their friends (Prentice \& Miller, 1993). We will determine whether a similar socialdistancing effect occurs for adolescent perceptions of their friends versus others' approval for drinking.

The present study will identify the extent to which both gender and culture moderate the strength of the hypothesized self-serving social-distancing biases. Such exaggerated perceptions of others are proposed to be self-serving to the extent that they recast one's own attributes in a more favorable light by making them appear more moderate and justifiable. Thus, they would be expected to be stronger when judging attributes that are negatively valued or controversial (Agostinelli \& Miller, 1994; Agostinelli, Sherman, Presson, \& Chassin, 1992; Campbell, 1986; Gerrard et al., 1991; Goethals, 1986; Suls \& Wan, 1987; Suls, Wan, \& Sanders, 1988). How then might culture and gender moderate the social-distancing effect? First, based on cross-cultural research comparing American and European adolescents, it is hypothesized that the social-distancing effect will be stronger in American youth than in Irish youth because there is stronger disapproval of drinking among American 
adolescents. For example, the majority of American youth disapprove of people who get drunk frequently, whereas only a minority of Irish youth disapprove (Hibell et al., 2000). More indirect evidence supporting a more accepting societal climate for youth drinking in Ireland than in America is that more Irish youth than American youth report drinking, heavy drinking, and having been drunk (Grube, Chen, Madden, \& Morgan, 1997; Hibell et al., 2000), and Irish youth perceive drinking to be less risky than do American youth (Hibell et al., 2000). Similarly, in another European country, Denmark, only a minority of youth disapprove of people getting drunk frequently in comparison to the majority of American youth who disapprove (Hibell et al., 2000).

Following from the hypothesis that self-enhancing overestimations will be stronger when estimating a behavior that is more disapproved of and evaluated more negatively (Agostinelli \& Miller, 1994; Agostinelli et al., 1992; Campbell, 1986; Goethals, 1986; Suls \& Wan, 1987; Suls et al., 1988), American youth overestimate the prevalence of underaged drinking more than do Danish youth, even though underaged drinking is actually more common among the Danish (Gibbons, HelwegLarsen, \& Gerrard, 1995). Gibbons et al. also attributed the stronger self-enhancing motives in American youth versus Danish youth to Americans being in a more competitive and individualistic culture (Gibbons et al., 1995; Hofstede, 1983). Such an orientation emphasizes the autonomous, independent, and unique nature of the individual, undermines social relatedness, and is more generally associated with selfenhancement motives (Markus, Kitayama, \& Heiman, 1996). To the extent that the Irish also tend to be less individualistic than Americans (Hofstede, 1983), one would expect less social distancing in Irish youth than in American youth.

Second, consider how gender might moderate the strength of the hypothesized social-distancing effects. We hypothesize that social-distancing effects will be stronger in girls than in boys because cross-culturally there is a tendency for girls to be more disapproving of drinking behaviors (e.g., getting drunk) than boys (Hibell et al., 2000). Furthermore, female drinking is disapproved of more than is male drinking (Rohsenow, 1983), and adolescent girls (relative to boys) also perceive their friends and parents to be more disapproving of their drinking (Grube \& Morgan, 1990). Thus, we hypothesize that there will be greater concern among girls to justify their drinking, and hence more social distancing than for boys when judging others' alcohol use and disapproval of drinking.

Finally, the present study has a third goal. Independent of exploring the socialdistancing effect and how it affects perceptions of others' drinking and approval, we will explore an implication of this effect for alcohol prevention and treatment. Providing students with accurate information about other students drinking attitudes (Hansen \& Graham, 1991 ; Prentice \& Miller, 1996; Shroeder \& Prentice, 1996) and drinking behaviors (Agostinelli, Brown, \& Miller, 1995; Hansen \& Graham, 1991) can decrease alcohol consumption by redefining what is normative. Even perceptions of one's close friends' drinking can be erroneous and in need of correction (Graham, Marks, \& Hansen, 1991; Kandel, 1996). Furthermore, perceptions of friends' drinking habits are more influential as normative standards in adolescent drinking than are perceptions of generalized others (Morgan \& Grube, 199 1). Independent of examining the social-distancing effect, we will examine whether perceptions of friends' drinking and disapproval are related more closely to students' own drinking than perceptions of more distal peers' drinking and disapproval and will consider cross-cultural and gender differences in these relationships. By doing so, we can identify which misperceptions are most important to correct.

To summarize, a primary goal of the present study is to examine whether the socialdistancing effects in risk and behavior judgments will generalize to high school 
students' perceptions of others' alcohol use and disapproval. We hypothesize that adolescents will self-servingly view their own drinking frequency as the most conservative, followed by best friends, other good friends, and finally more distal same-aged peers at their own and other schools. Similarly, we hypothesize that in estimating disapproval, best friends will be attributed the most conservative disapproval, followed by other good friends, and more distal same-aged peers at their own and other schools. We also will examine how culture and gender moderate these biases.

Based on previous research, we expect that American students (Hibell et al., 2000) and girls (Grube \& Morgan, 1990; Hibell et al., 2000; Rohsenow, 1983) will perceive more disapproval for their drinking. We thus hypothesize that social-distancing effects will be stronger among Americans (relative to Irish) and among girls (relative to boys). Finally, we will examine whether perceptions of friends' drinking and disapproval of drinking are related more strongly to students' drinking than those same perceptions for other students more generally, and how these relations may vary cross-culturally and between genders.

\section{Method}

The present study is based on analyses of data from the second wave of a threewave longitudinal survey of high school and post-primary school students from the greater San Francisco Bay Area in the United States and the greater Dublin area in Ireland (Grube et al., 1997) 3 .3 Within each country, a sample of schools was obtained and then grade levels were selected randomly for inclusion at each school. The schools were stratified for gender, size, and type of school.

\section{Procedure}

Participants: Participants were 1,26 1 American high school students in $10^{\text {th }}$ to 12 th grades and 1,293 Irish post-primary students in the equivalent grades (third level through leaving certificate) who completed self-administered surveys. The American sample comprised of 574 boys and 687 girls from eight public and parochial schools. They ranged in age from 14 to 20 years old $(M=17.0)$. The ethnic makeup of the American sample was 54\% European American, 15\% AsianiPacific Islander, $12 \%$ Latino, $6 \%$ African American, $1 \%$ Native American, and $12 \%$ of othedmixed ethnicity. The Irish sample was comprised of 594 boys and 699 girls from 14 schools. They ranged in age from 14 to 22 years old $(M=16.6)$.

Survey administration. Each of the participating schools was paid a small fee (\$2) for each student who participated. Students in the selected class levels were tested in their regular classrooms or in another group setting within the school. The survey sessions were supervised by trained research personnel and lasted about 40 to 50 min. Before each session, a member of the research staff explained that the study was concerned with smoking, drinking, and drug use, and told the students that the survey was voluntary and assured them of the complete anonymity and confidentiality of their responses. Students were instructed not to put their names anywhere on the survey materials, and the need for truthfil answers was emphasized.

\section{Measures}

Own drinking frequency. To measure their own frequency of drinking, participants in both countries were asked how often in the past 12 months they had had a whole drink. Separate items were included for beer, wine, wine cooler, and hard liquor.

\footnotetext{
${ }^{3}$ Additional questionnaires were administered by mail at Time 2, but to keep the administration mode constant, only those participants who were present for the in-class survey administration are included in the present analyses.
} 
Respondents in Ireland were asked the same questions, with cider included among the listed alcoholic beverages. The 10 possible responses ranged from 1 (not at all) to 10 (every day). These responses were rescaled using category midpoints to reflect the respective number of days annually that respondents drank. The resulting scale compromised 10 values ranging from 0 days to 365 days. Thus, for example, the response category 2-3 timesper month was recoded as 30 days annually.

Perceived drinking frequency of others. To measure the perceived alcohol use of others, respondents in both countries were asked how often they thought their best friend, other good friends, most students their age at their own school, and most students their age at other schools have had at least one whole drink of beer, wine, wine cooler, or hard liquor during the past 12 months. Respondents in Ireland were asked the same question, with cider included among the listed alcoholic beverages. The possible response categories were the same as those used for own drinking and ranged from 1 (not at all) to 10 (every day). They were rescaled to reflect the number of days annually that the targets were estimated to have had a drink.

Perceived disapproval of drinking. To measure perceived disapproval of drinking, respondents in both countries were asked to rate on 5-point scales how much they thought their best friend, other good friends, most students their age at their own school, and most students their age at other schools would disapprove if they were to have 2 or 3 whole drinks of an alcoholic beverage. Responses ranged from 1 (disapprove very strongly) to 5 (not disapprove) and were recoded so that numerically higher scores corresponded to greater disapproval.

\section{Results}

All dependent variables were log-transformed prior to analyses. Reported means are anti-logs of the mean logged scores adjusted for age in all cases.

\section{Perceived Disapproval of Drinking}

A mixed-design $2 \times 2 \times 4$ (Culture: American vs. Irish x Gender: Girls vs. Boys x Target: Best Friend, Other Good Friends, Most Students My Age at My School, Most Students My Age at Other Schools) ANCOVA controlling for age was conducted on perceived disapproval scores. The effect for age was significant, with older students believing that others were generally less disapproving of their drinking $(\beta=-.18), F(1$, $2386)=82.05, p<.0001$. In addition, all three main effects obtained statistical significance. First, the Target main effect was consistent with the social distancing hypothesis, $F(3,7161)=377.08, p<.0001, \eta^{2}=.13$. Estimates of disapproval were highest for best friend $(M=2.0)$, followed by other good friends $(M=1.7)$, same-aged students at own school $(M=1.3)$, and same-aged students at other schools $(M=$ 1.2). Painvise comparisons reveal that although judgments made for the last two targets (i.e., same-aged students at one's own versus other schools) did not differ, $F(3,7161)=0.55, n s$, judgments did significantly differ between best friend and other good friends, $F(3,7161)=158.50, p<.001$; and between other good friends and same-aged students at own school, $F(3,7161)=715.85, p<.001$. Second, the predicted Culture main effect also obtained with American students, relative to Irish students, believing that others disapproved of drinking more $(M=1.4$ vs. 1.3$), F(1$, $2386)=171.09, p<.0001, \eta^{2}=.06$. Third, a small Gender main effect obtained, with girls $(M=1.6)$ believing that others disapproved of their drinking more than did boys $(M=1.5), F(1,2386)=17.56, p<.0001, \eta^{2}=.01$.

Finally, the two predicted two-way interactions obtained. First, as depicted in Figure 1, a statistically significant Culture $x$ Target interaction qualified the obtained Culture and Target main effects, with more social distancing between the targets for Americans than for Irish, $\mathrm{F}(3,7161)=77.94, p<.0001, \eta^{2}=.03$. Simple effect tests of culture at each target level revealed that although American students reported significantly more disapproval at each target level, the difference became 
respectively smaller as the target groups became more distant: best friend, $F(1$, $7161)=568.69, p<.001, \eta^{2}=.07$; other good friends, $\mathrm{F}(1,7161)=358.98, p<.001$, $\eta^{2}=.05$; same-aged students at their own school, $\mathrm{F}(1,7161)=31.48, p<.001, \mathrm{\eta}^{2}<$ .01 ; and same-aged students at other schools, $F(1,7161)=15.68, p<.001, \eta^{2}<.01$.

Second, as depicted in Figure 2, a small but statistically significant Gender x Target interaction qualified the main effects for Gender and Target with more social distancing between the targets for girls than for boys, $F(3,7161)=25.86, p<.0001$, $\eta^{2}=.01$. Simple effects tests reveal that girls reported significantly more disapproval than did boys for both best friend, $F(1,7161)=94.66, \mathrm{p}<.001, \mathrm{\eta}^{2}=.01$; and other good friends, $F(1,7161)=50.05, p<.001, \eta^{2}<.01$. Yet, gender did not reliably affect estimates assigned to same-aged high school students more generally at either own school, $\mathrm{F}(1,7161)=0.04, n s$; or at other schools, $\mathrm{F}(1,7161)=0.04$, ns. No other interactions obtained (all $p s>.10$ ).

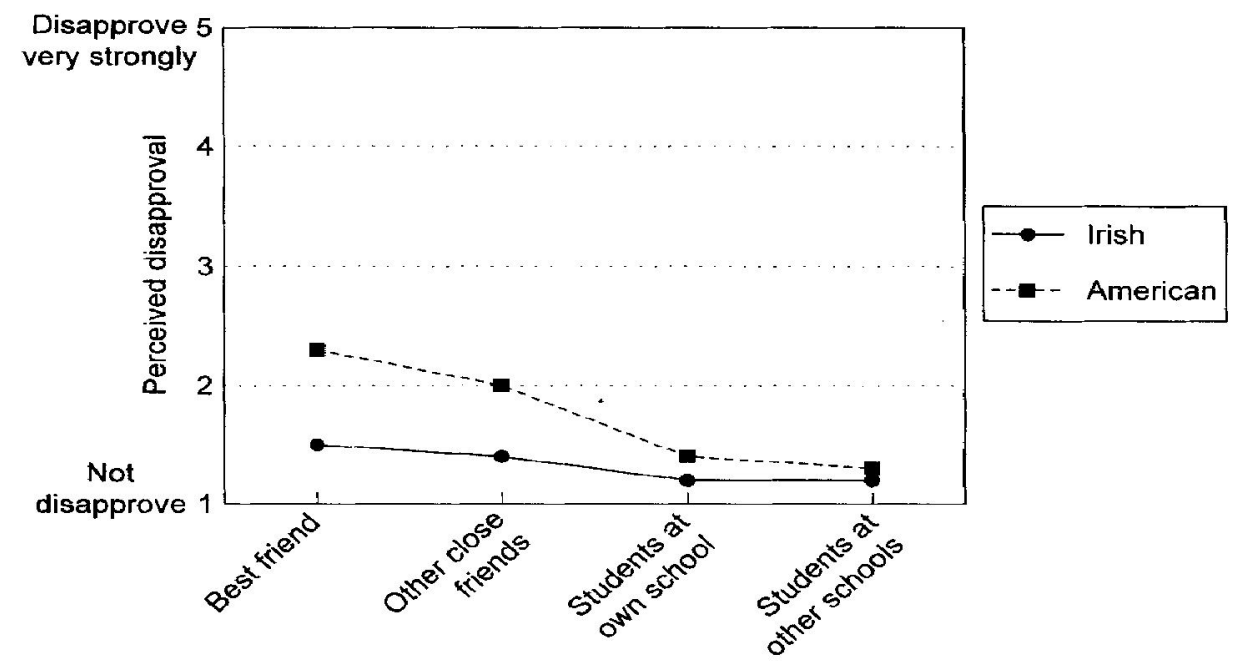

Figure 1. Perceived disapproval of drinking as a function of target and culture.

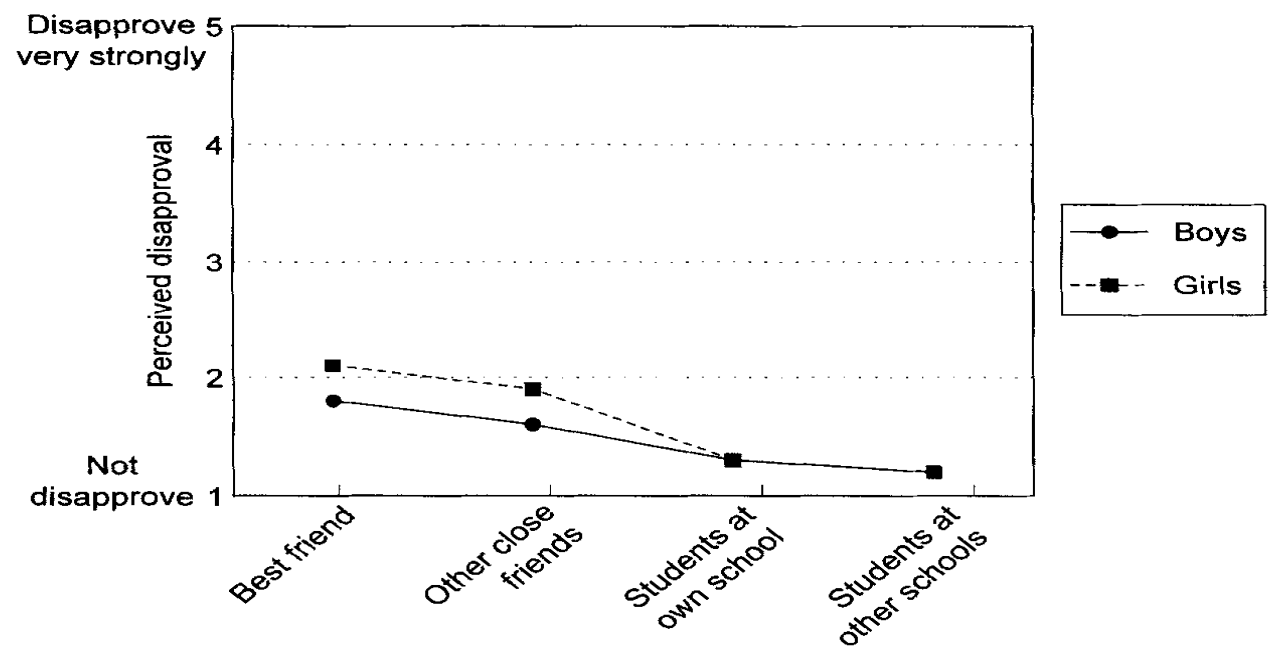

Figure 2. Perceived disapproval of drinking as a function of target and gender.

Perceived Drinking Frequency for Self and Others

A mixed-design $2 \times 2 \times 5$ (Culture: American vs. Irish x Gender: Girls vs. 
Boys x Target: Self, Best Friend, Other Good Friends, Most Students My Age at My School, Most Students My Age at Other Schools) ANCOVA controlling for age effects was conducted on perceived drinking frequency scores. Older students reported higher drinking frequency estimates overall $(p=.37), F(1$, $2371)=370.94, p<.0001$. In addition, the three main effects corresponding to the three design factors obtained statistical significance. First, the Target main effect was consistent with the social distancing hypothesis, $F(4,9488)=828.98, p<.0001, \eta^{2}=$ .25. Perceived alcohol use was lowest for self ( $M=5.6$ days), followed by best friend ( $M=6.9$ days), other good friends ( $M=10.5$ days), same-aged students at own school ( $M=22.9$ days), and same-aged students at other schools ( $M=24.8$ days). All pairwise comparisons between means for adjacent target levels were significant, $F s(4,9488)=69.05,308.06,1,174.30$, and 12.27 ,ps <. 001, respectively. Second, the Culture main effect obtained, with American students estimating less frequent drinking $(M=8.9$ days) than did Irish students $(M=16.2$ days), $F(I, 2371)=174.23, p$ $<.0001, \mathrm{n}^{2}=.06$. Third, a small Gender main effect obtained, with girls $(M=11.4$ days) estimating less frequent drinking than did boys $(M=12.7$ days $), F(1,2371)=$ 5.61, $p<.02, \eta^{2}<.01$.

Again, the two predicted two-way interactions obtained. As depicted in Figure 3, a statistically significant Culture $x$ Target interaction indicates that there was more social distancing between the targets for Americans than for the Irish, $F(4,9488)=$ $81.69, \sim<.0001, \eta^{2}=.02$. The largest differences between Irish youth and American youth were observed for own and best friend's drinking, with the estimates converging for the more distal targets. Simple effect tests reveal that Irish (relative to American) students judged significantly more frequent drinking for themselves, $F(1$, $9488)=365.85, p<.001, \eta^{2}=.04$; their best friends, $F(1,9488)=507.80, p<.001$, $\eta^{2}=.05$; other good friends, $F(I, 9488)=321.56, p<.001, \eta^{2}=.03$; and same-aged students at their own school, $\mathrm{F}(\mathrm{I}, 9488)=14.24, p<.001, \eta^{2}<.01$. Culture did not reliably affect estimates of drinking by same-aged students at other schools, $F(1$, 9488) $=1.53, n s$.

Further, as depicted in Figure 4, a small statistically significant Gender x Target interaction qualified the Target and Gender main effects with more social distancing between the targets for girls than for boys, $F(4,9488)=23.02, p<.0001, \eta^{2}=.01$. Simple effects tests reveal that girls (relative to boys) reported significantly less frequent drinking for themselves, $F(1,9488)=22.86, p<, 001, q 2<.01$; best friend, $\mathrm{F}(1,9488)=43.38, p<.001, \eta^{2}<.01$; and other good friends, $\mathrm{F}(1,9488)=32.92, p<$ $.001, \mathrm{n}^{2}<.01$. Yet, for the more distal targets, girls reported significantly more drinking for same-aged students at their own school, $F(1,9488)=5.88, p<.001, \eta^{2}<$ .01 ; and same-aged students at other schools than did boys, $F(1,9488)=11.58, p<$ $.001, \eta^{2}<.01$.

\section{Correlations Between Own Drinking Frequency and Normative Perceptions of Drinking Frequency and Disapproval}

The strength of the relations between one's own drinking frequency and perceptions of others' drinking frequency and disapproval was examined as a function of the varying target groups (Table 1). In all cases, perceptions of others' drinking frequency and disapproval were correlated significantly with own drinking. Nonetheless, the correlations between students' own drinking frequency and their perceptions of their best friend's and other close friends' drinking frequency and disapproval were significantly greater than all of the same correlations for students at their own and other schools (all ps $<.00 \mathrm{l}$ ). This general pattern held, regardless of culture and gender. 


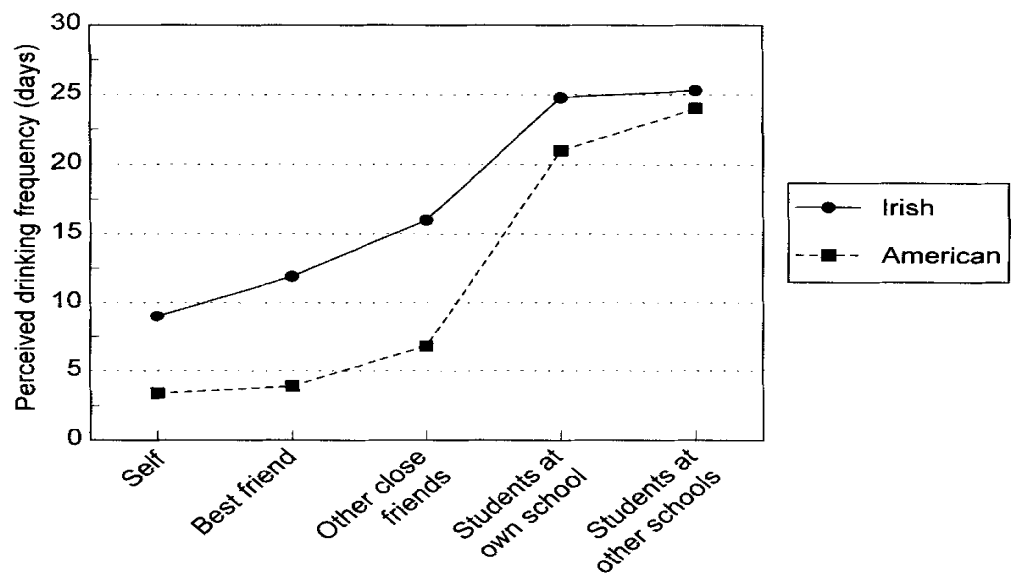

Figure 3. Perceived drinking frequency as a function of target and culture.

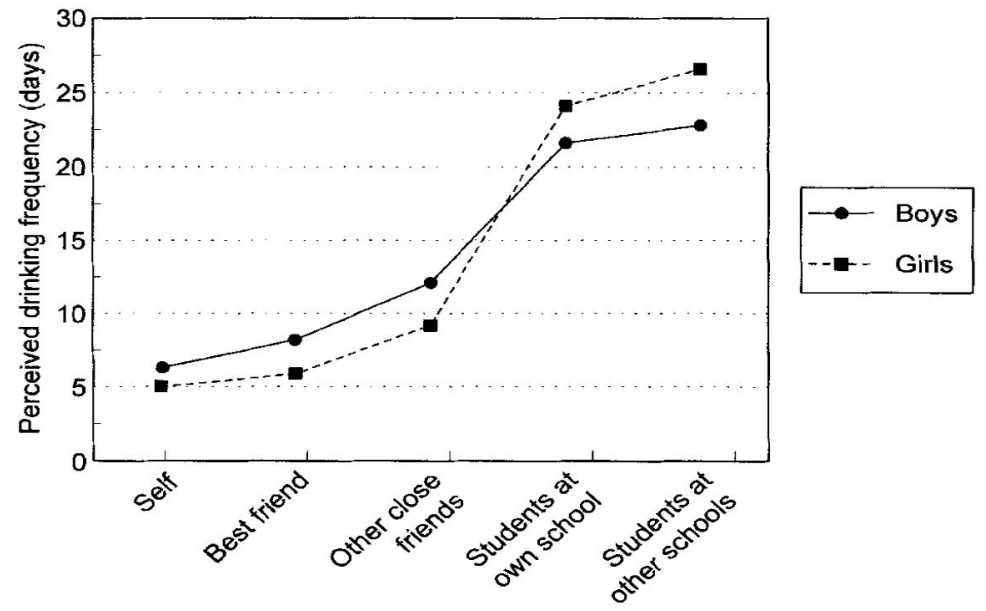

Figure 4. Perceived drinking frequency as a function of target and gender.

Table 1 Correlation of Perceived Drinking Frequency and Perceived Disapproval With Own Drinking Frequency as a Function of Target and Culture

\begin{tabular}{llllll}
\hline & Total $^{\mathrm{a}}$ & Boys $^{\mathrm{b}}$ & Irish & \multicolumn{3}{c}{ Girls $^{\mathrm{c}}$} & Boys $^{\mathrm{a}}$ & Girls $^{\mathrm{e}}$ \\
\hline Perceived drinking frequency & & & & & \\
$\quad$ Best friend & .67 & .70 & .63 & .61 & .67 \\
Other friend & .61 & .63 & .58 & .55 & .60 \\
Same school & .22 & .23 & .16 & .28 & .25 \\
$\quad$ Own school & .17 & .16 & .13 & .24 & .22 \\
Perceived disapproval & & & & & \\
$\quad$ Best friend & -.44 & -.41 & -.45 & -.34 & -.45 \\
Other friend & -.40 & -.30 & -.43 & -.25 & -.44 \\
Same school & -.16 & -.11 & -.18 & -.12 & -.15 \\
$\quad$ Other school & -.12 & -.11 & -.13 & -.12 & -.09 \\
\hline
\end{tabular}

a'Perceived drinking frequency, $\boldsymbol{n}=2,383$; perceived disapproval, $\boldsymbol{n}=2,376$.

${ }^{\mathrm{b}}$ Perceived drinking frequency, $\boldsymbol{n}=534$; perceived disapproval, $\boldsymbol{n}=534$.

${ }^{\mathrm{C}}$ Perceived drinking frequency, $\boldsymbol{n}=642$; perceived disapproval, $\boldsymbol{n}=650$.

${ }^{\mathrm{d}}$ Perceived drinking frequency, $\boldsymbol{n}=550$; perceived disapproval, $\boldsymbol{n}=540$.

${ }^{\mathrm{e}}$ Perceived drinking frequency, $\boldsymbol{n}=650$; perceived disapproval, $n=645$. 


\section{Discussion}

We set out to determine whether the same social-distancing effect that occurs for drinking-related attitudes (Prentice \& Miller, 1993) and behavior judgments (Baer et al., 1991) in young adults would generalize to adolescents' drinking-related judgments. Indeed, this generalization occurred, with adolescents attributing the most conservative alcohol use to themselves and their best friends and respectively less conservative use to other good friends, other students at their own school, and students at other schools. These findings replicate a robust social-distancing effect documented across a variety of measures, including risk judgments for negative outcomes (e.g., Gerrard et al., 1991; Linville et al., 1993; Perloff \& Fetzer, 1986; vanderPiigt et al., 1993; Weinstein, 1980, 1982; Wills, 1981), sexual attitudes and behaviors (e.g., Agostinelli \& Seal, 1998), and drinking-related attitudes and behaviors (e.g., Baer et al., 1991; Prentice \& Miller, 1993).

Why might adolescents exhibit this social-distancing effect? Our results are most consistent with a motivational account. Adolescents likely justified their own alcohol use in a self-serving manner by perceiving it as more moderate than others. Given that one's behavior on a socially sensitive issue has implications about oneself, making downward comparisons and viewing oneself as less extreme than others can serve an ego-defensive function (Gerrard et al., 1991; vanderPligt et a]., 1993; Wills, 198 1). Our adolescents distanced themselves from others by judging their friends' and peers' alcohol use as less responsible than their own. As students distanced themselves more from their peers by exaggerating others' drinking rates, they also likely perceived their own alcohol use as being more proper and moderate (Roche, 1986).

Also consistent with a motivational account, our participants rated their friends as less permissive than others more generally. Specifically, they attributed both a more frequent drinking rate and less disapproval of drinking to other students than to their friends, thus possibly sparing themselves from the negative implications of having friends who engage in disapproved behaviors and hold questionable attitudes. Judging one's friends more conservatively than other students is a robust finding in the risk estimation literature (e.g., Linville et al., 1993; Perloff \& Fetzer, 1986), sexual attitudes literature (e.g., Agostinelli \& Seal, 1998), and drinking literature (e.g., Baer \& Carney, 1993; Baer et al., 1991; Prentice \& Miller, 1993). People may be motivated to resist acknowledging less desirable attributes for those they are close to for the same reasons of fear and anxiety reduction that minimize their perceptions of their own risks (Perloff \& Fetzer, 1986). In particular, self-serving judgments extend more readily to those with whom we identify (Burger, 1981; Pettigrew, 1979).

Alternatively, a cognitive availability explanation for the obtained social-distancing effect can account for the greater judged similarity to one's friends than to other more generalized peers in estimating drinking frequency, though it is not clear how it could explain the direction of this effect. Specifically, a cognitive availability account assumes that judgments about others are based on the information that is most available about that group at the time of judgment (Tversky \& Kahneman, 1973). Given that friends' attitudes and behaviors are more similar to each other than to less familiar others (Byrne, 1971; Kandel, 1978; Newcomb, 1961), then students should have more available to them and recall more drinking rates similar to their own for their friends than for distal peers. This would lead to judging one's own drinking rate as more similar to that of one's friends than to more generalized peers. Thus, a cognitive availability account can explain the social ordering effect in terms of similarity. Yet, it still cannot explain why both one's friends' and other students' drinking are always judged as more frequent and extreme than one's own. In sum, a 
motivational account can best explain both the ordering of the various targets in the social-distancing effect, as well as the direction of that effect.

To further test a motivational account, we examined the roles of culture and gender in moderating the strength of the social-distancing effect. First, it was hypothesized that with stronger evidence in American youth than in European youth for a general disapproval of drinking (Hibell et al., 2000), there would be more motivation to bias information in a self-serving direction for American than for Irish adolescents (Agostinelli \& Miller, 1994). In fact, American youth did perceive more disapproval for their drinking than did Irish youth, and, as predicted, the observed social-distancing effect was more pronounced in American youth than in Irish youth. Replicating the evidence for stronger self-serving biases in American versus European (Danish) youth when estimating the prevalence of deviant behaviors (Gibbons et al., 1995), the stronger self-serving biases observed here in American youth versus European Irish youth also supports the contention that Americans raised in a more individualistic and competitive culture (Hofstede, 1983) will be more self-enhancing.

This replication supports broader cross-cultural evidence for stronger self-enhancing self-other comparisons (e.g., in unrealistic optimism, overemphasizing the uniqueness of one's positive qualities) in North Americans than for other countries, although the latter countries are typically non-Western Asian countries (e.g., Markus et al., 1996). The present replication in North American youth versus European youth indicates that even between different Western cultures, there may be significant variation in the strength of these biases. Yet, future research needs to identify what mediates those cultural differences. Being raised in an individualistic culture that places a greater emphasis on being an autonomous, independent individual (Hofstede, 1983; Markus et al., 1996) or a culture that disapproves more of specific behaviors, or both of these factors, could be responsible for differences in selfenhancement.

Second, we examined whether gender moderated the strength of the socialdistancing effect. Cross-culturally, there is a tendency for girls to be more disapproving of drinking behavior than boys (Hibell et al., 2000). Further, given that drinking in females is disapproved of more than in males (Rohsenow, 1983) and that adolescent girls (relative to boys) also perceive their friends and parents to be more disapproving of their own drinking (Grube \& Morgan, 1990), we hypothesized that there would be greater concern among girls to justify their drinking by engaging in more social distancing. Overall, girls did perceive more disapproval for drinking than did boys, although this effect was relatively weak. As predicted, the observed socialdistancing effect was more pronounced in girls than in boys when judging both others' disapproval for drinking and drinking frequency. Interestingly, although boys judged drinking rates to be higher among both themselves and their friends than did girls, this difference converged and even reversed when judging the more distal target groups of other same-aged students at one's own and other schools. The stronger social-distancing effects observed in girls are consistent with greater overestimation biases observed in college-aged women when judging the prevalence of drinking-related behaviors (e.g., Agostinelli \& Miller, 1994) and sexual behaviors (e.g., Seal \& Agostinelli, 1996).

Although our results offer consistent evidence for a motivational account, future research should determine the exact mechanisms responsible for the socialdistancing effect. We hypothesized that judgments would be more self-enhancing and that more distancing would occur when those judgments were self-implicating, and that this would be truer when there was more judged disapproval for drinking. Indeed, we found stronger social-distancing effects for both American youth (relative 
to Irish youth) and girls (relative to boys), with both Americans and girls also perceiving more disapproval for drinking. Yet, in prior research, we found similar overestimation biases in judging others' heavy drinking, although not all participants judged heavy drinking to be socially unacceptable (Agostinelli \& Miller, 1994). This suggests that eliciting self-serving motives did not depend on concern over the social acceptability of one's behavior, but rather on minimally recognizing that one's behaviors had potentially threatening or enhancing implications. Indeed, not all individuals weigh the importance of normative concerns in guiding their judgments and behaviors. Some place more weight on their own personal attitudes and evaluations of the behavior (Fishbein \& Ajzen, 1975; Snyder, 1987).

Without having measured participants' attitudes toward their own drinking, we cannot ascertain which participants may have overestimated others' drinking to justify how normal their own drinking appeared in their own eyes and which participants may have overestimated others' drinking to justify how their own drinking would be judged by others. Future research should explore the moderating influence of individual differences in weighing personal versus normative concerns on self-enhancing biases (Fishbein \& Ajzen, 1975; Snyder, 1987).

To summarize, the self-serving social-distancing effect observed in other populations and for other target behaviors (e.g., Agostinelli \& Seal, 1998; Baer \& Carney, 1993; Baer et al., 1991; Linville et al., 1993; Perloff \& Fetzer, 1986; Prentice \& Miller, 1993; vander Pligt et al., 1993; Weinstein, 1980, 1982; Wills, 1981) was replicated in high school and secondary students' perceptions of others' drinking behaviors and disapproval of drinking. Students estimated their own alcohol use as the most conservative, with somewhat higher drinking rates assigned to their friends and considerably higher rates attributed to other students. Similarly, they estimated their friends to be more disapproving of their own drinking than other students more generally. As predicted, both culture and gender moderated the strength of these social-distancing effects. They were stronger where youth disapprove of drinking more, among both American youth relative to Irish, and girls relative to boys. We interpreted these results as most consistent with a motivational account, proposing that social distancing is a means of viewing one's own drinking as more moderate and justifiable.

With social-distancing effects proposed to be the product of motivated social cognition, both motivational and cognitive processes have the potential to contribute, yet different factors may affect which type of process predominates (Kruglanski, 1996). Thus, future research should be designed to predict differentially when socialdistancing effects are more the product of a motivated versus a cognitive process.

For example, when social-distancing effects are the product of a motivation to seek normalization and support for one's behavior, there should be stronger evidence for them after the self has been threatened. Indeed, following failure experiences, there is stronger evidence for self-serving perceptions of others (Agostinelli et al., 1992; Dunning, Leuenberger, \& Sherman, 1995; Sherman, Presson, \& Chassin, 1984) than when failure has not occurred. Further, if social-distancing effects are the product of a self-serving process, then they should be more evident in non-depressed and high self-esteem individuals, as they are believed to be functional in maintaining these individuals' more positive views of themselves (Baumeister, 1998; Campbell, 1986; Taylor \& Brown, 1988). Finally, if social-distancing effects are self-serving, they should be stronger when one is judging attributes and behaviors that have personal relevance and importance, as such factors affect the extent to which motivational concerns will be aroused (Campbell, 1986; Kruglanski, 1996; Tesser, 1988). 
Regardless of the theoretical mechanism responsible for our findings, the observed social-distancing effects in perceived drinking rates have important implications for the prevention and treatment of adolescent alcohol use. Perceptions of peer drinking and disapproval are both significant risk factors for adolescent alcohol use and problems (e.g., Grube \& Morgan, 1990; Hansen, 1994; Morgan \& Grube, 1991; Petraitis et al., 1995; Windle et al., 1996). Indeed, perceiving others' drinking as relatively common and others' attitudes as less disapproving can perpetuate risky drinking by serving either as a permissive subjective norm in guiding behavior (Ajzen, 1989; Ajzen \& Fishbein, 1980) or as an after-the-fact justification for risky drinking (Agostinelli \& Miller, 1994; Gerrard et al., 1996; Grube \& Morgan, 1990). Both perceptions of others' drinking behavior and disapproval of drinking were related to our adolescents' actual drinking behavior. Yet, their perceptions of their friends' disapproval and drinking frequency were related more strongly to their own drinking than were their corresponding perceptions for more distal peers. This latter result suggests that attempts to decrease alcohol consumption by providing accurate information about others' attitudes (Hansen \& Graham, 1991; Prentice \& Miller, 1996; Schroeder \& Prentice, 1998) and behaviors (Agostinelli et al., 1995; Hansen \& Graham, 199 I), should focus on correcting judgments about friends' drinking and approval.

\section{References}

Agostinelli, G., Brown, J. M., \& Miller, W. R. (1995). Effects of normative feedback on consumption among heavy drinking college students. Journal of Drug Education, 25,3 1-40.

Agostinelli, G., \& Miller, W. R. (1994). Drinking and thinking: How does personal drinking affect judgments of prevalence and risk? Journal of Studies on Alcohol, 55,327-337.

Agostinelli, G., \& Seal, D. W. (1998). Social comparisons of one's own with others' attitudes toward casual and responsible sex. Journal of Applied Social Psychology, 28, 845-860.

Agostinelli, G., Sherman, S. J., Presson, C. C., \& Chassin, L. (1992). Self protection and self-enhancement biases in estimates of population prevalence. Personality and Social Psychology Bulletin, 18,63 1-642.

Ajzen, I. (1989). Attitude structure and behavior. In A. R. Pratkanis, S. J. Breckler, \& A. G. Greenwald (Eds.), Attitude structure and function (pp. 241-274). Hillsdale, $\mathrm{NJ}$ : Lawrence Erlbaum.

Ajzen, I., \& Fishbein, M. (1980). Understanding attitudes and predicting social behavior. Englewood Cliffs, NJ: Prentice-Hall.

Baer, J. S., \& Carney, M. M. (1993). Biases in the perceptions of the consequences of alcohol use among college students. Journal of Studies on Alcohol, 54. 54-60

Baer, J. S., Stacy, A., \& Larimer, M. (1991). Biases in the perception of drinking norms among college students. Journal of Studies on Alcohol, 52,580-586.

Baumeister, R. F. (1998). The self. In D. T. Gilbert, S. T. Fiske, \& G. Lindzey (Eds.), The handbook of social psychology (4th ed., Vol. 1, pp. 680-740). Boston, MA: McGraw-Hill.

Beck, K. H., \& Treiman, K. A. (1996). The relationship of social context of drinking, perceived social norms, and parental influence to various drinking patterns of adolescents. Addictive Behaviors, 21,633-644.

Burger, J. M. (1981). Motivational biases in the attribution of responsibility for an accident: A meta-analysis of the defensive attribution hypothesis. Psychological Bulletin, 90,496-5 12.

Byrne, D. E. (1 97 1). The attraction paradigm. New York, NY Academic Press. 
Campbell, J. D. (1 986). Similarity and uniqueness: The effects of attribute type, relevance, and individual differences in self-esteem and depression. Journal of Personality and Social Psychology, 50,28 1-294.

Dunning, D., Leuenberger, A., \& Sherman, D. A. (1 995). A new look at motivated interference: Are self-serving theories of success a product of motivational forces? Journal of Personality and Social Psycholoa, 69, 58-68.

Fishbein, M., \& Ajzen, I. (1975). BelieJ; attitude, intention, and behavior: An introduction to theory and research. Reading, MA: Addison-Wesley.

Gerrard, M., Gibbons, F. X., Benthin, A. C., \& Hessling, R. M. (1996). A longitudinal study of the reciprocal nature of risk behaviors and cognitions in adolescents: What you do shapes what you think, and vice versa. Health Psychology, 15, 344354.

Gerrard, M., Gibbons, F. X., \& Warner, T. D. (1991). Effects of reviewing risk relevant behavior on perceived vulnerability among women marines. Health Psychologv, 10, 173-179.

Gibbons, F. X., Helweg-Larsen, M., \& Gerrard, M. (1995). Prevalence estimates and adolescent risk behavior: Cross-cultural differences in social influence. Journal of Applied Psychology, 80, 107- 121.

Goethals, G. R. (1986). Fabricating and ignoring social reality: Self-serving estimates of consensus. In J. Olson, C. P. Herman, \& M. P. Zanna (Eds.), Relative deprivation and social comparison: The Ontario Symposium on Social Cognition (Vol. IV, pp. 135-157). Hillsdale, NJ: Lawrence Erlbaum.

Graham, J. W., Marks, G., \& Hansen, W. B. (1991). Social influence process: Affecting adolescent substance use. Journal of Applied Psychology, 76, 289-3 15.

Grube, J. W., Chen, M-J., Madden, P. A., \& Morgan, M. (1997). Drinking and drinking problems: A cross-national comparison of Irish and American adolescents. European Addiction Research, 3, 75-82.

Grube, J. W., \& Morgan, M. (1990). Attitude-social support interactions: Contingent consistency effects in the prediction of adolescent smoking, drinking, and drug use. Social Psychology Quarterly, 53, 329-339.

Hansen, W. B. (1994). Prevention of alcohol use and abuse. Preventive Medicine, 23,683-687

Hansen, W. B., \& Graham, J. W. (1991). Preventing alcohol, marijuana, and cigarette use among adolescents: Peer pressure resistance training versus establishing conservative norms. Preventive Medicine, 20,414-430.

Hibell, B., Anderson, B., Ahlstrom, S., Balakireva, O., Bjamason, T., Kokkevi, A., \& Morgan, M. (2000). The 1999 ESPAD Report: Alcohol and other drug use among students in 30 european countries. Stockholm, Sweden: The Swedish Council for Information on Alcohol and Other Drugs (CAN), The Pomipdou Group at the Council of Europe.

Hofstede, G. (1983). Dimensions of national cultures in fifty countries and three regions. In J. Deregowski, S. Dzirawiec, \& R. Annis (Eds.), Explications in crosscultural psychology (pp. 335-355). Lisse, The Netherlands: Swets \& Zeitlinger.

Kandel, D. B. (1978). Similarity in real-life adolescent friendship pairs. Journal of Personality and Social Psychologv, 36,306-3 12.

Kandel, D. B. (1996). The parental and peer contexts of adolescent deviance: An algebra of interpersonal influences. Journal of Drug Issues, 26, 291-298.

Kruglanski, A. W. (1996). Motivated social cognition: Principles of the interface. In E. T. Higgins \& A. W. Kruglanski (Eds.), Socialpsychology: Handbook of basic principles (pp. 493-520). New York, NY Guilford.

Linville, P. W., Fischer, G. W., \& Fischhoff, B. (1993). AIDS risk perceptions and decision biases. In J. B. Pryor \& G. D. Reeder (Eds.), The social psychology of $H Z V$ infection (pp. 5-38). Hillsdale, NJ: Lawrence Erlbaum. 
Markus, H. R., Kitayama, S., \& Heiman, R. J. (1996). Culture and "basic" psychological principles. In E. T. Higgins \& A. W. Kruglanski (Eds.), Social psychology: Handbook of basic principles (pp. 857-913). New York, NY Guilford.

Morgan, M., \& Grube, J. W. (1991). Closeness and peer group influence. British Journal of Social Psychology, 30, 159- 169.

Newcomb, T. M. (1961). The acquaintance process. New York, NY Holt, Rinehart, \& Winston.

Perloff, L. S. (1983). Perceptions of vulnerability to victimization. Journal of Social Issues, 39,4 1-61.

Perloff, L. S., \& Fetzer, B. K. (1986). Self-other judgments and perceived vulnerability to victimization. Journal of Personality and Social Psychology, 50, 502-5 10.

Petraitis, J., Flay, B. R., \& Miller, T. Q. (1 995). Reviewing theories of adolescent substance use: Organizing pieces in the puzzle. Psychological Bulletin, I1 7, 6786.

Pettigrew, T. (1 979). The ultimate attribution error: Extending Allport's cognitive analysis of prejudice. Personality and Social Psychology Bulletin, 5, 46 1-476.

Prentice, D. A., \& Miller, D. T. (1993). Pluralistic ignorance and alcohol use on campus: Some consequences of misperceiving the social norm. Journal of Personality and Social Psychology, 64,243-256.

Prentice, D. A., \& Miller, D. T. (1996). Pluralistic ignorance and the perpetuation of social norms by unwitting actors. In M. Zanna (Ed.), Advances in experimental social psychology (Vol. 29, pp. 161-209). New York, NY Academic Press.

Roche, J. P. (1986). Premarital sex: Attitudes and behavior by dating stage. Adolescence, 21, 107- 121.

Rohsenow, D. J. (1 983). Drinking habits and expectancies about alcohol's effects for self versus others. Journal of Consulting and Clinical Psychology, 51, 752 - 756

Schroeder, C. M., \& Prentice, D. A. (1998). Exposing pluralistic ignorance to reduce alcohol use among college students. Journal of Applied Social Psychology, 28,2 150-2180.

Seal, D. W., \& Agostinelli, G. (1996). College students' perceptions of the prevalence of risky sexual behaviour. AIDS Care, 8,453-466.

Sherman, S. J., Presson, C. C., \& Chassin, L. (1984). Mechanisms underlying the false consensus effect: The special role of threats to the self. Personality and Social Psychology Bulletin, 10, 127- 138.

Snyder, M. (1987). Public appearances in private realities: The psychology of selfmonitoring. New York, NY Freedman.

Suls, .I.\&, Wan, C. K. (1987). In search of the false uniqueness phenomenon: Fear and estimates of social consensus. Journal of Personality and Social Psychology, $52,211-217$.

Suls, J., Wan, C. K., \& Sanders, G. S. (1988). False consensus and false uniqueness in estimating the prevalence of health-protective behaviors. Journal of Applied Social Psychology, 18,66-79.

Taylor, S. E., \& Brown, J. D. (1988). Illusion and well-being: A social psychological perspective on mental health. Psychological Bulletin, 103, 193-2 10.

Tesser, A. (1988). Toward a self-evaluation maintenance model of social behavior. In L. Berkowitz (Ed.), Advances in experimental social psychology (Vol. 21, pp. 181227). New York, NY Academic Press.

Tversky, A., \& Kahneman, D. (1973). Availability: A heuristic for judging frequency and probability. Cognitive Psychology, 5, 207-232.

vanderpligt, J., Otten, W., Richard, R., \& vandervelde, F. (1993). Perceived risk of AIDS: Unrealistic optimism and self-protective action. In J. B. Pryor \& G. D. Reeder (Eds.), The social psychology of HIV infection (pp. 39-58). Hillsdale, NJ: Lawrence Erlbaum.

Weinstein, N. D. (1980). Unrealistic optimism about future life events. Journal of Personality and Social Psychology, 39,806-820. 
Weinstein, N. D. (1982). Unrealistic optimism about susceptibility to health problems. Journal of Behavioral Medicine, 5,441 -460.

Wills, T. A. (1981). Downward comparison principles in social psychology. Psychological Bulletin, 90,245-271.

Windle, M., Shope, J. T., \& Bukstein, 0. (1996). Alcohol use. In R. J. DiClemente, W. B. Hansen, \& L. E. Ponton (Eds.), Handbook of adolescent health risk behavior (pp. 115-1 59). New York, NY Plenum. 